Maternal phenylketonuria, newborn screening program, developmental delay.

\section{P434 TYROSINEMIA TYPE 1: A CASE REPORT}

1,2Mahmoud Rashad*, 'Carmen Nasser. 'King Fahd Hospital, Al Baha, Saudi Arabia; ${ }^{2} \mathrm{Al}$ Azher University, Cairo, Egypt

\subsection{6/archdischild-2019-epa.770}

Introduction Tyrosinemia type 1 is an $\mathrm{AR}$ inherited metabolic disorder attributed to deficiency of Fumarylacetoacetatehydrolase, which is a terminal enzyme in the metabolism of tyrosine. The gene for this enzyme has been mapped to the long arm of chromosome 15 . Its prevalence has been reported as 1: 100.000 . The patients with tyrosinemia expire in the early years of their lives. There is a markedly increased risk of hepatocellular carcinoma among the survivors.

Case report An Saudi 8-month-old male infant presented with complaints of abdominal distension, fever, jaundice, melena and disturbed level of consciousness for 3 days prior to admission to PICU (in King Fahd Hospital, Al-Baha). He was the $1^{\text {st }}$ child of 1 st degree consanguineous parents.

His motor and mental development were delayed. One day after admission, the infant developed repeated daily attacks of neurological crises in bouts of irritability, crying with increased tone and deep tendon reflexes in the lower limbs.

On physical examination patient looked sick, pale, jaundiced and drowsy. He had rachitic signs. There was mild lower limb edema. Fine crackles were audible bilaterally on the chest. Abdomen was distended. Liver was palpable 5 $\mathrm{cm}$ below right costal margin. Spleen was just palpable below left costal margin. There was positive shifting dullness, with scrotal edema. The infant was drowsy, with poor vision, and hypertonic, with exaggerated deep tendon reflexes.

Hematological screening CBC showed anemia and thrombocytopenia. CRP was positive and urine analysis showed albumin \& RBCs.

Biochemical examination showed that BUN: $12.5 \mathrm{mmol} / \mathrm{L}$, creatinine $27 \mathrm{umol} / \mathrm{L}$, glucose: $2.9 \mathrm{mmol} / \mathrm{L}, \mathrm{Ca}: 2.2 \mathrm{mmol} / \mathrm{L}$, phosphorus: $0.64 \mathrm{mmol} / \mathrm{L}, \mathrm{Mg}: 0.57 \mathrm{mmol} / \mathrm{L}$, albumin: 28 $\mu \mathrm{mol} / \mathrm{L}$, T. bilirubin: $35 \mu \mathrm{mol} / \mathrm{L}$, direct bilirubin: $17 \mu \mathrm{mol} / \mathrm{L}$, alkaline phosphatase 426U/L, AST: 65U/L, gamma GT: 130U/ L, LDH: 566U/L, ammonia: $121 \mu \mathrm{mmol} / \mathrm{L}$. Coagulation screening was abnormal. Blood Alpha feto protein was very high, ABG examination showed compensated metabolic acidosis.

Tracheal aspirate C/S showed MRSA The left wrist graphy showed evidence of rickets. Abdomen ultrasonography revealed hepatosplenomegaly with moderate ascites. Liver examination showed multiple hyperechoic masses. Abdominal CT showed hepatomegaly with multiple hyperdense masses, splenomegaly and ascites. CT brain showed cerebral atrophy.

Blood phenylalanine, tyrosine and methionine levels were all high. Urine examination showed increased levels of organic acids.

So, the infant was diagnosed as tyrosinemia type I and was prescribed a phenylalanine and tyrosine restricted diet (special formula milk) and received treatment for Vit. D resistant rickets. Following treatment, patient showed much clinical and laboratory improvement, but not to the safe level to conduct liver biopsy.

\section{P435 RETINOPATHY OF PREMATURITY PREVALENCE AND RISK FACTORS IN DEVELOPING COUNTRIES}

${ }^{1}$ Reza Saeidi, ${ }^{2}$ Azra Izanloo*, ${ }^{2}$ Raheleh Habibnejad. 'Department of Pediatrics, Mashhad University of Medical Sciences, Mashhad, Iran, Islamic Republic of; ${ }^{2}$ Razavi Cancer Research Center, Razavi Hospital, Imam Reza International University, Mashhad, Iran, Islamic Republic of

\subsection{6/archdischild-2019-epa.771}

Retinopathy of prematurity prevalence and risk factors in developing countries

Introduction Retinopathy of prematurity (ROP) is an avoidable disorder in preterm infants, which can lead to blindness unless it is diagnosed and treated at early stages.

Objectives The goal of this study is to determine the prevalence of ROP and its predisposing factors in preterm infants admitted to NICU at community hospital, Mashhad, Iran.

Method ROP screening was done for infants that admitted to NICU weighing less than $1500 \mathrm{mg}$ and a gestational age of 32 weeks or less was conducted from January 2018 to 2019 in. A total of 149 neonates (89 males and 60 females) underwent retinal evaluation using indirect ophthalmoscopy during the fourth week and were periodically followed up.

Prenatal risk factors of ROP were evaluated using univariate analysis.

Results Of the 149 neonates under study, 42 were ROP positive out of whom $17(40 \%)$ were at stage 2, $12(29 \%)$ at stage $1,2(5 \%)$ at stage 3 and $2(5 \%)$ at stage 4 while19 $(21 \%)$ of newborns were treated with Avastin injection. The results of univariate analysis showed that there was a significant difference between ROP occurrence and gestational age, birth weight and oxygen therapy duration. $(\mathrm{p}=0.0001)$. However, there was no significant relationship between the ROP occurrence and gender $(p=0.55)$, stage of disease and gestation age $(\mathrm{p}=0.208)$ and oxygen therapy duration $(\mathrm{p}=$ $0.314)$.

Conclusion The estimated prevalence of ROP in this study was $28 \%$ that was higher than developed countries. Gestational age, oxygen therapy and low birth weight are known risk factors of ROP. The risk of ROP in a gestational age of less than 32 weeks is 4.2 times higher than the gestational age of more than 32 weeks. Therefore, it is essential to make plan for the most effective control over the predisposing factors like oxygen therapy, preventing premature delivering, and incidence of birth asphyxia in NICU.

Retinopathy, preterm infant, prevalence, developing countries

\section{P436 KNOWLEDGE AND PRACTICE OF PULSE OXIMETRY SCREENING FOR CRITICAL CONGENITAL HEART DEFECT IN NEWBORN INFANTS BY PAEDIATRICIANS IN BENIN}

${ }^{1}$ Yakoubou Annatou*, ${ }^{2}$ Adjagba Mahouna Philippe, ${ }^{1}$ Tchiakpe Nicole. ${ }^{1}$ Faculte Des Sciences De La Sante, Universite D'abomey-Calavi, Cotonou, Benin; ${ }^{2} E$ Des Sciences De La Sante, Universite D'abomey-Calavi, Cotonou, Benin

\subsection{6/archdischild-2019-epa.772}

Introduction Pulse oximetry screening for critical congenital heart defect in newborn infants is not widely used even in developed countries. In Benin, the diagnosis of congenital heart disease is often late, making the surgical treatment impossible 